[Bird Claiborne, L., \& Smith A. (2007). Tertiary Education for Students with Impairments: A Code of Practice at the Beginning of the Journey. New Zealand Annual Review of Education, 16, 73-87]

\section{Tertiary Education for Students with Impairments: A Code of Practice at the Beginning of the Journey}

\author{
LISE BIRD CLAIBORNE AND ALEXANDRA SMITH
}

\section{Abstract:}

In this article we review recent innovations in policies and practice for inclusion of tertiary education students with impairments. During 2006 New Zealand's first code of practice, Kia Ōrite (Achieve, 2004) was widely available, though it was just beginning to affect practice. This review centres the arrival of the Code in the context of tertiary education access and greater focus in government policy, particularly from the Ministry of Education and the Office of Disability Issues. Discussion of policy and practice in Aotearoa New Zealand is set within wider international policy and research issues. We conclude with a brief discussion of likely future directions.

$\mathrm{T}$ his review pays homage to New Zealand's growing body of research being built around inclusive education in the tertiary education sector. One of New Zealand's most important objectives for its Social Research fund, as outlined by the Foundation for Research, Science and Technology (2006), is the creation of an inclusive society. A focus on inclusive practices also provides a basis for altering various educational practices in order to provide learning environments that promote educational achievement for students with impairments.

In New Zealand, it is difficult to trace the history of students with impairments involved in tertiary education, much less to find out how well students have been included in classrooms and given access to resources that could enhance their further studies. Information on people with disabilities has only been collected statistically since 1998 (Dyson, 2005). Changes clearly have also happened in New Zealand from that time, since the percentage of students with impairments in tertiary education increased from 3.3 percent of all domestic tertiary

\section{Lise Bird Claiborne and Alexandra Smith}

students in 1998 (7,500 students with impairments) to 5.4 percent of the much bigger pool of students in 2004 (24,660 students: Dyson, 2005).

A crucial beginning for this opening of tertiary education to more students with impairments was the passing of the Human Rights Act in 1993; this acknowledged disability as an area of discrimination. During the 1990s, support for university students with impairments gradually moved from counselling centres to students support services as the emphasis changed from medical to social concerns.

The Tertiary Education Strategy 2002-2007 (Ministry of Education, 2002) provided as one of its key objectives "to remove the barriers to inclusion for disabled people accessing tertiary education" in order to increase the number of people with impairments achieving skills and qualifications. This goal was also echoed in the New Zealand Disability Strategy. In response to these policy goals, late in 2004, Achieve, the National Post-Secondary Education Disability Network, developed and published Kia Ōrite-Achieving Equity: New Zealand Code of Practice for an Inclusive Tertiary Education Environment for Students with Impairments (Achieve, 2004), New Zealand's first code of practice providing guidelines to assist tertiary education providers. Kia Ōrite was widely available by 2006, raising new questions for tertiary education.

Several lines of current educational policy, research and practice in New Zealand have relevance for the inclusion of students with impairments in tertiary education. For the purposes of this review, we use the term "students with impairments", following Kia Ōrite and the New Zealand Disability Strategy (Ministry of Health, 2001), which explicitly includes a great range of people who identify as having various kinds of impairments or as disabled. The paper begins with an overview of how well students with impairments are faring in tertiary study in New Zealand. This is followed by a brief introduction to some current theoretical debates in order to place the policy and research issues in a wider international context. In this section, we note particular tensions between special education and inclusion, and the "social" versus "medical model" of disability, debates that are useful in understanding the direction of recent government initiatives around tertiary education and inclusion. We then give an outline of some key research projects in New Zealand and overseas, in this small but growing field of empirical research. Finally, we consider directions for the future, when there is likely to be increasing engagement with disability concerns as they intersect with issues of diversity in the tertiary education sector. 


\section{Achievements of Students with Impairments in Tertiary Study}

In launching Kia Örite, The Minister for Disability Issues, Ruth Dyson, pointed to the success experienced by students with impairments in tertiary education.

From unpublished Ministry of Education data, we know that disabled or impaired learners perform similarly to learners without disability or impairment. The same percentage of learners with disabilities as those without $-40 \%$ - has successfully completed their qualifications within five years of starting. And a similar number of learners with disabilities - $49 \%$ - as those without - $48 \%$ - have completed or are still enrolled within five years of starting.

And, at $26 \%$ in 2003, the first-year attrition rate for disabled learners was less than that for learners without disabilities - at 34\%. (Dyson, 2005)

Referring to these findings, the Minister concluded, "Capability then, is clearly not the issue." However, we would like to add a caveat: though some students do well with current levels of resourcing and support, there are still gaps in provision that could be addressed to ensure that all students with impairments reach their potential. As an example of support, Dyson referred to the Tertiary Students with Disabilities Special Supplementary Grant, funding only available to a very select group of tertiary students characterised as having "high" needs, e.g., for technological resources and trained support staff. However it is the Kia Orite code of practice that has been explicitly designed to have the biggest impact on improving the experiences of education of tertiary students with impairments.

In commenting on the chequered history of access to higher education by disabled students in the UK, Colin Barnes (2007, p. 135) noted that, "Until the 1990s, most British universities were virtually inaccessible to disabled students and staff." He argued that the changes since the 1990s were largely "due to the politicization of disability by the international disabled people's movement" and to the rise of the field of disability studies. In 1999 the UK's Quality Assurance Association created a code of practice for students with disabilities in higher education (QAA, 2007).

In 1996 in Australia, the Australian Vice Chancellors' Committee (AVCC) launched guidelines to assist universities in providing inclusive services to people with disabilities. A national code of practice for students with disabilities was created in 1998 that included guidelines for inclusive practice (Tasmanian State Government, 1999). The AVCC document was updated with legislative changes and developments in practice in 2006 (AVCC, 2006). This document included sections on policy and administration, teaching and learning, and campus life and services. A website (CATS, 2007) was also created to resource staff to provide inclusive pedagogy that met with best practice standards.

International research supports the New Zealand finding that students with impairments perform well at university when supportive services are available. If a student is adequately supported and/or these barriers are removed, assessment of academic skills will be the focus of attendance at the institution. For example, Jorgensen et al. (2005) studied a single tertiary institution in Canada with specific policies and practices to assist disabled students. They found that students with disabilities did as well in their studies as students without disabilities. The creation of codes of practice for tertiary institutions is part of a movement to help institutions to provide appropriate educational experiences for students with impairments through the creation of explicit guidelines aimed ultimately at improving student achievement and enjoyment of tertiary study.

These encouraging statistics for students with impairments must be read with a grain of salt, however, since students with impairments are less likely than non-impaired peers to enter tertiary education. Jorgensen et al. (2005) noted that in Canada students with disabilities are almost $25 \%$ less likely than students without disabilities to have any post-secondary education. The situation in Aotearoa New Zealand is comparable, with only $27 \%$ of students with impairments continuing on with education after leaving school (versus $34 \%$ for students without impairments: Achieve, 2004, p. 46).

There may also be mismatches in the transition sector for students and parents considering post-compulsory education options. The spotlight will now be on student-focused planning and development of education and employment goals at the secondary level. For example, such planning could be included in individual education plans (IEPs) as a matter of course. More work could be done to bridge the gap between the compulsory education sector "special needs" provision into post-secondary supported independent learning. For learners returning to education as mature students, community agencies can also play a part in facilitating this transition in partnership with tertiary bodies. 


\section{Global Issues Regarding Inclusion of Students with Impairments}

The global concern with inclusion in educational policies has really become dominant only in the past 10 to 15 years. A key policy document was the Salamanca Statement on Special Needs Education (UNESCO, 1994), which showed a commitment to the right to education for all and a willingness to "recognize the principle of equality of opportunity for children, youth and adults with disabilities in primary, secondary and tertiary education carried out, in so far as possible, in integrated settings" (UNESCO, 1994, p. 1).

Slee and Allan (2001) described a current controversy between an older paradigm of "special education" and a new force from disability studies that eschews a more "medical" model of individual pathology to describe learning difficulties. This follows from a social model of disability, whereby a person is only disabled insofar as the surrounding environment creates barriers for them. Slee and Allan point out that conditional language often lets institutions off the hook, giving an "out" or alternative to the difficulties involved in creating programmes truly open to a variety of learners. They argued for very careful examination of language used in policies and practice codes to consider more hidden discourses about the kind of inclusion actually being promoted. To illustrate this, they considered problems with policies in two states of Australia in which inclusion was mooted but schools were easily able to opt out of any serious consideration of changing their practices. We think this tension is addressed by the creation of a code of practice that focuses on concrete action required by teachers and institutions to demonstrate inclusion.

This tension between paradigms was also noted by Kearney and Kane (2006). They pointed to the change from "mainstream" education to a greater dismantling of "special" educational concerns in the inclusion movement. They further proposed that New Zealand was currently going through something like a third wave of upheaval, since many remnants of the former focus of special education were still in existence, despite the broadening policy mandates on inclusion. Kearney and Kane also argued that objectives and goals would not ensure inclusion; rather, that the long hard road of challenging old knowledge and using "a different way of thinking based on a different knowledge base" (p. 216) would be required, involving "a different view of disability". The critique present in this paper reiterated the argument for a social model rather than a medical model of disabilities:

\section{Lise Bird Claiborne and Alexandra Smith}

The change must also involve a different view of disability; one not based upon individual pathology and deficit, but one that views disability as a social and political construction. (Kearney \& Kane, 2006, p. 216)

This distinction between biomedical views of disability as an internal deficit in the person, versus a more social constructionist view emphasising external barriers as the cause of disability, was first mooted by Oliver (1984). Recent theorising in disability studies has gone beyond this dualism to posit more postmodern views of the body (e.g., Goggin \& Newell, 2003; Kuppers, 2003). We propose that most of the New Zealand policy reviewed here is informed by a social model of disability rather than a medical one. It will be interesting to see how future policies respond to the continuing change in the landscape of disability studies theory and politics.

There is one view that most international disability commentators agree on: that inclusion is a journey rather than an end-point. Rather than seeing inclusion as an achievable goal, with some institutions clearly being "inclusive" and others failing to meet the mark, a group of UK researchers argued that inclusion and exclusion are complex, ongoing processes "enacted moment-by-moment by pupils and teachers" (Benjamin et al., 2003, p. 547). Though the authors were discussing inclusion in primary schooling, we think there is much wisdom in this view of inclusion as an ideal that must be vigilantly pursued in practice. How well were things going in New Zealand in 2006 ?

\section{A Watershed Year for Aotearoa}

The UN General Assembly formally adopted the United Nations Convention on the Rights of Persons with Disabilities on 13 December 2006 (UN, 2006). New Zealand had a significant role in the development of this treaty; for example, Don MacKay of New Zealand was Chairman of the Ad Hoc UN Committee that worked towards the Convention. The Office of Disability Issues (ODI), liaising with New Zealand disability organisations, as well as with the Human Rights Commission and the Ministry of External Affairs and Trade, was actively involved in the drafting of this convention (ODI, 2007). Countries which are signatories to this convention are required to improve public access to buildings and transport for people with disabilities, combat negative stereotypes and prejudice, and generally actively work to improve the rights of people with disabilities. 
Under the auspices of the Ministry of Health, the New Zealand Health and Disability Strategy reflects changes to the Health and Disability Commissioner Act that came into force in 2004. This development of the strategy aimed to reflect consumer rights and participation in health and disability issues. The ODI also created a Disability Strategy Implementation Plan, to link work done by the ODI and the Health sector to the New Zealand Disability Strategy 2001 objectives. The goal was to improve consumer participation in design and operation of health and disability services, and included advocacy services and distribution of relevant information to consumers and community agencies. The key areas were participation, partnership, and protection. Consumers are encouraged and supported to actively engage with their public health service to ensure quality service delivery. A disability perspective is also included in everyday work of the service in line with the Disability Strategy. The references to partnership and rights (advocacy) suggest that there is room for inclusion of the social model of disability in looking at health provision, in this way influencing and possibly redefining disability in the health context.

The Ministry of Education in 2006 put concerns about tertiary students with impairments higher up its list of policy priorities. While this was mostly related to issues of compulsory schooling, many of the broader statements signalled a general concern for issues of disability that could be read as extending to the tertiary education sector. The Ministry of Education Annual Report 2006 (Ministry of Education, $2006 \mathrm{~b}$ ), in its discussion of "Reducing inequalities in education outcomes 2005/06" (p. 118), begins with its focus on "ensuring people in all groups, regardless of socio-economic status, ethnicity, disability or gender, succeed to the best of their ability and are positively engaged in effective and meaningful learning." The report shows an awareness of the linking of issues such as culture/ethnicity and gender with disability concerns, an intersection mirrored in the international literature.

The Ministry of Education report mainly focussed on disability issues with regard to special education provision. The Ministry, according to this report, "has continued to invest in parent support and development programmes, relationships with iwi, Pasifika communities, parents of children with special education needs and organisations representing the disabilities sector" (p. 10). While the focus on parents would seem less likely to apply to tertiary students, the policy still signals important community links with Māori and Pasifika communities that are crucial for tertiary students. There was also mention of "participation in a review of long-term disability support" (p. 11) as part of inter-agency integration of education into wider social policies. This report also (commendably) included mention of the Disability Strategy Working Group and Disability Strategy Reference Group. The Ministry had created a plan based on the Disability Strategy to ensure that "any barriers for staff that identify as differently-abled were identified and removed, and that the Ministry's capability and practice reflects the needs of this group and of our clients" (p. 26). In terms of specific supports for issues of impairment, the Ministry of Education settled a collective agreement over 2005/06 for support staff in schools, namely "assistants to teachers of students with severe disabilities, and special education assistants" (p. 73). Extension of these concerns to tertiary education support staff is then an important consideration for the future.

In its forecasting to Parliament for the 2006/2007 financial year, the Ministry of Education (2006a) clearly mentioned disabilities as evident in awareness of disparities in achievement for "learners with special education needs, disabilities and people for whom English is a second language" (p. 17). Education strategies are thus targeted towards "different communities (Māori Education Strategy, Pasifika Education Plan, strategies for providing education support for people with disabilities and special education needs)" (p. 18). There was also an expressed commitment to greater collection of data specifically concerning "learners with special education needs, those with disabilities, and gifted and talented students" (p. 25) as well as Māori and Pasifika students. In terms of "Strengthening outcomes for students with special education needs" (p. 57), there was particular focus on two documents, the Special Education Action Plan: Better Outcomes for Children 2006-2011 and The New Zealand Disability Strategy - Making a World of Difference: Whakanui Oranga. However it must also be said that the focus seemed to be largely on school-based disability concerns, without specific linking of tertiary education concerns with disability. The focus on special education in these documents could signal problems for their translation to tertiary education. It was also not clear whether the linkages between Māori or Pasifika educational concerns and disability issues would be maintained. The importance of considering disability issues in cultural context is presented clearly in Kia Ōite. For example, a suggestion for best practice in support staff is to have "Māori staff within disability services and staff with impairments within Māori services" (Achieve, 2004, p. 26). 
This section on government directions for 2006 should not end without noting that the third reading of the New Zealand Sign Language (NZSL) bill was passed in April, giving NZSL the status of an official language of New Zealand (along with English and Māori). This will have huge implications for facilitating Deaf People's participation in accessing education and other government services. It also gives more recognition to the role of NZSL interpreters (see ODI, 2006). This should also improve access to learning at the tertiary level for Deaf students and others who use NZSL.

\section{Implementation of the Code of Practice for Aotearoa New Zealand}

The Kia Orite Code of Practice was designed to create a vision and best practice guidelines for all areas of the tertiary environment, including teaching and learning, providing a basis for evaluation on progress towards achieving an inclusive teaching and learning environment. The Code was particularly concerned with the following educational practices: instructional design, student experiences of success in classroom, independent research and online learning, training and support for staff and students, and future study and career options for students.

Dyson's (2005) launch of the Code of Practice noted its links to the objectives of the Disability Strategy, notably for its purpose "to improve post-compulsory education options for disabled people" (Strategy Action 3.8) and promoting "the provision of education and training opportunities to increase the individual capacity of disabled people to move into employment" (Action 4.1). She also noted that the Code would help institutions to meet the government's commitment to the disability sector, and expressed a positive view of current practice.

Already we're seeing progress in the sector. The July 2005 report of the Teaching Matters Forum - the body leading the development of a national centre for tertiary teaching excellence - has identified that excellent practice within the sector is building the success of learners with impairment.

However, the Forum has also identified that barriers still exist. The Forum contends that these need to be addressed through teaching and professional development. And that more evidence-based research into the teaching and learning issues facing these learners is needed. Many of these learners are Maori and Pasifika and many may be in mature age groups. Some are involved with more than one education institution. The issues are therefore very complex. (Dyson, 2005)
This comment shows the importance of taking the Code further within institutions, to follow through with professional development initiatives. Because much statistical monitoring has not in the past tracked ethnicity and disability simultaneously, there is not enough known about requirements of Māori and Pasifika learners with impairments. Yet it is clear, for example, that there are at least as many Māori with impairments as in society in general, though cultural groups may have distinctive profiles in terms of particular age- and gender- related impairments (Statistics New Zealand, 2003).

\section{Research on Tertiary Inclusion for Students with Impairments}

\section{International}

Providing the right kinds of support for students with impairments is not a simple matter. A study of six colleges of further education in the UK, involving a large questionnaire study as well as interviews with a small sample of disabled students (Ash et al., 2005), found that disabled students did not always know what support services were available at their institution. Another troubling finding from this study was that staff were often seen as attempting to be helpful without, unfortunately, being knowledgeable about the services that could benefit disabled students. There was also some concern about the lack of friendship networks between disabled and non-disabled students. These findings seem to fit Dyson and Milward's (1999, p. 159) conclusion that in the UK, at least in the late 1990s, there was a "mismatch between educational inclusion and social exclusion" once students have left the more supportive secondary school environment to take on work or further study.

Another review of UK literature indicated that little research on disability issues in the tertiary education sector actually included the voices of students themselves (Hall, Healey \& Harrison, 2002). Commenting on this research on a visit to New Zealand, Mick Healey emphasised the importance of ensuring that disabled students' voices are heard in research, by ensuring that students are included as research participants (Healey, 2006). Healey also advocated for collaboration by academic staff and staff working within services that provide disability support in joint research on the reality of inclusive teaching and learning.

\section{New Zealand}

Little New Zealand research has been done on the impact of teaching practices on tertiary students with impairments. Studies of the impact 
of support on beginning tertiary students have not always included students with impairments as part of the research design. For example, in the best evidence synthesis on the impact of support for tertiary student outcomes - rather than on policy initiatives - provided by Massey University researchers (Prebble et al., 2004), there was only one direct reference to disability issues. However there was considerable emphasis on diversity of programmes and resources as well as on the impact of cultural diversity in the student population. After their review of over 250 studies on student support, Prebble et al. (2004) concluded that "assimilating diverse students into existinginstitutional cultures" ( $\mathrm{p}$. 10) was enhanced by welcoming institutional practices, social induction programmes, the chance to become part of a learning community, good advice about courses, approachable staff, additional instruction for difficult courses and provision of peer mentoring services. Research also pointed to ways to help students adapt well to university settings, emphasising the importance of lack of discrimination, assisting students to feel safe and valued, as well as varied courses that catered to student diversity. The review concluded that much more New Zealand based research was needed on these support issues. While we agree wholeheartedly with the need for more national research, particularly regarding students with impairments, we would take these conclusions further. The stated focus of Prebble et al. on assimilation to existing norms is not in keeping with inclusive strategies in education. The latter emphasise dynamic, reciprocal changes in people's understandings and behaviour rather than a process of fitting minority groups into dominant structures. We argue that there are important inter-connections between issues of culture, impairment and gender that should be explored by researchers.

A research project currently underway ${ }^{1}$ is exploring more about the experiences of students with impairments at the university, as well as about staff and students who do not identify as having an impairment. The research is designed as part of an appreciative inquiry (Cooperrider \& Whitney, 2005), to examine one university's current strengths as well as areas for further development of the Code in practice. The research design follows the research strategy suggested by Healey (2006). The research takes as its central feature a focus on voices of students themselves and their descriptions of actual positive practices of inclusion in the university. The research also aims to gather more information about wider practices of inclusion with group interviews (Kamberelis \& Dimitriadis, 2005) of both lecturing and administrative staff and students who do not identify as having an impairment. The goal of the research is to explore participants' understanding and experience of the goals of inclusion within one faculty of the university, with the possibility of expansion to a larger study of other disciplines later.

\section{Future Directions}

This review indicates the huge increase in policy concern (with its implications for practice) around inclusion of tertiary students with impairments in Aotearoa New Zealand in 2006. While we are encouraged by the great number of government initiatives that show an increasing interest in issues of impairment and disability, there was less evidence of its direct impact on practice, in enhancing the experiences of New Zealand tertiary students with impairments.

There seems to have been a major change in the focus on inclusion in the area of disability, moving from a focus on compulsory schooling towards post-secondary/tertiary education options. Much of the research on inclusion refers to special education or special needs settings in primary and secondary education. The next step forward could be to consider the transition tools available to create opportunities for young people with disabilities to move into tertiary education. Teachers' professional development programmes could also be developed further to include specific methodologies for inclusive best practice.

We also think there are exciting future possibilities for research into inclusive education for students in Aotearoa New Zealand conducted by students with impairments themselves. Research could be encouraged that explores the narrative experiences of students with impairments at the intersections of culture, gender, sexuality and ethnicity. There is also a wealth of more exploratory qualitative research, involving diverse performers and commentators, that could have much to offer in informing inclusive practice. Greater openness to creative projects within disability studies could lead to wider engagement by research with crucial contemporary inclusion concerns, which could have an important impact on development of policy in this field.

\section{Note}

1. This research project, due for completion in late 2007, is being carried out by Lise Bird Claiborne, Ava Gibson, Sue Cornforth, Alexandra Smith, Joanna Clover and Grant Cleland. 


\section{References}

Achieve. (2004). Kia Ōrite, achieving equity: New Zealand code of practice for an inclusive tertiary education environment for students with impairments. Wellington: Ministry of Education.

Ash, A., Bellew, J., Davies, M., Newman, T., \& Richardson, L. (2005, first published 1997). Everybody in? The experience of disabled students in further education. In K. Topping \& S. Maloney (Eds), The RoutledgeFalmer reader in inclusive education (pp. 235-249). Abingdon, Oxfordshire: RoutledgeFalmer.

Australian Vice Chancellors Committee (AVCC). (2006). AVCC guidelines relating to students with a disability. Retrieved on January 31, 2007 from <www.equity.qut.edu.au/programs/forstudents/ disability_services/AVCCDisabilityGuidelinesMay06.pdf $>$

Creating Accessible Teaching and Support (CATS). (2007). Creating accessible teaching and support. Retrieved on January 30, 2007 from $<$ www.adcet.edu.au/cats $>$.

Barnes, C. (2007). Disability, higher education and the inclusive society. British Journal of Sociology of Education, 28(1), 135-145.

Benjamin, S., Nind, M., Hall, K., Collins, J., \& Sheehy, K. (2003). Moments of inclusion and exclusion: Pupils negotiating classroom contexts. British Journal of Sociology of Education, 24(5), 547-558.

Cooperrider, D. L., \& Whitney, D. (2005). Appreciative inquiry: A positive revolution in change. San Francisco, CA : Berrett-Koehler.

Dyson, Ruth. (2005, December). Address to the Disability in Education Conference, University of Auckland. Retrieved on November 12, 2006 from <www.labour.org.nz/RuthDyson/speeches and releases/ address_disAbility_rdnews_061205/index.html>

Dyson, A., \& Millward, A. (1999). Falling down the interfaces: From inclusive schools to an exclusive society. In K. Ballard (Ed.), Inclusive education: International voices on disability and justice (pp. 152-166). London: Falmer.

Foundation for Research, Science and Technology (FRST). (2006). Investing in innovation for New Zealand's future: Statement of intent 2006-2009. Wellington: FRST.

Goggin, G., \& Newell, C. (2003). Digital disability: The social construction of disability in new media. Lanham, MD: Rowman and Littlefield.

Hall T., Healey M., \& Harrison M. (2002) Disabled students and fieldwork: From exclusion to inclusion. Transactions of the Institute of British Geographers, 27(2), 213-231.

Healey, Mick. (2006, July 24). Listening to students: The experiences of disabled students of learning at university. Seminar presented at Victoria University of Wellington.

Jorgensen, S., Fichten, C. S., Havel, A., Lamb, D., James, C., \& Barile, M. (2005). Academic performance of college students with and without disabilities: An archival study. Canadian Journal of Counselling, 39(2), 101-117.

Kamberelis, G., and Dimitriadis, G. (2005). Focus groups: Strategic articulations of pedagogy, politics, and inquiry. In N. K. Denzin \& Y. S. Lincoln (Eds.), The Sage handbook of qualitative research. 3rd Ed. (pp. 887-958). Thousand Oaks, CA: Sage.

Kearney, Alison, \& Kane, Ruth. (2006). Inclusive education policy in New Zealand: Reality or ruse? International Journal of Inclusive Education, 10(2-3), 201-219.

Kuppers, P. (2003). Disability and contemporary performance: Bodies on edge. New York: Routledge.

Ministry of Education. (2002). Tertiary education strategy 2002/07. Wellington: Ministry of Education.

Ministry of Education. (2006a). Educate: Ministry of Education statement of intent 2006-2011. Wellington: Ministry of Education.

Ministry of Education. (2006b). Ministry of Education /Te Tāhuhu o Te Mātauranga annual report for the year ended 30 June 2006. Presented to the House of Representatives pursuant to section 44(1) of the Public Finance Act 1989. Wellington: Ministry of Education.

Ministry of Health. (2001). The New Zealand Disability Strategy: Making a world of difference/Whakanui Oranga. Wellington: Office of Disability Issues. Retrieved on January 29, 2007 from <www.odi.govt.nz/publications/nzds/index.html>

Office for Disability Issues (ODI). (2006). History. Retrieved on January 30, 2007 from <www.odi.govt.nz/what-we-do/nzsl-history.html>.

Office for Disability Issues (ODI). (2007). UN Convention on Rights of Disabled People: Common questions. Retrieved on January 29, 2007 from < www.odi.govt.nz/what-we-do/un-convention-questions.html>

Oliver, M. (1984). The politics of disability. Critical Social Policy, 4(11), 21-32. 
Prebble, T., Hargraves, H., Leach, L., Naidoo, K., Suddaby, G., \& Zepke, N. (2004). Impact of student support services and academic development programmes on student outcomes in undergraduate tertiary study: A synthesis of the research. Report to the Ministry of Education. Wellington: Ministry of Education.

Quality Assurance Association (QAA). (2007). Code of practice for the assurance of academic quality and standards in higher education. Section 3: Students with disabilities - October 1999. Retrieved on January 30, 2007 from < www.qaa.ac.uk/academicinfrastructure/codeOfPractice/ section3/default.asp $>$

Slee, R., \& Allan, J. (2001). Excluding the included: A reconsideration of inclusive education. International Studies in Sociology of Education, 11(2), 173-190.

Statistics New Zealand. (2003). New Zealand Disability Survey Snapshot 2: Māori. Retrieved on January 30, 2007 from

$<$ www2.stats.govt.nz/domino/external/pasfull/pasfull.nsf/web/ Media + Release +2001+New +Zealand + Disability+Survey+ Snapshot +2+Māori?open>

Tasmanian State Government. (1999). Inclusive practice is good practice: A Tasmanian State disability liaison officer initiative. Hobart: University of Tasmania. Retrieved on January 25, 2007 from

<services.admin.utas.edu.au/gateways/IPIGP_pubs/text/appB.htm>

United Nations (UN). (2006). General Assembly adopts groundbreaking Convention, optional protocol on rights of persons with disabilities. Retrieved on January 29, 2007 from

$<$ www.un.org/News/Press/docs/2006/ga10554.doc.htm>

United Nations Educational, Scientific and Cultural Organization (UNESCO). (1994). Final Report: World conference on special needs education: Access and equality. Paris: UNESCO.

\section{The authors}

Lise Bird Claiborne is a Senior Lecturer in the School of Education Studies at Victoria University of Wellington. She has wide research and teaching interests in the areas of difference, diversity and inclusion.

Alexandra Smith is a Project Worker with Disability Support Services at Victoria University of Wellington. She is currently a researcher involved in a study of inclusion for tertiary students with impairments. 